\title{
Evaluation of a Nursing Continuing Education Programme
}

\author{
ShAdiA A. H. Yousuf, MsN", KHAIRIA Y. NASSER, PhD*, JENNY LiTTLEWOOD, PhD ${ }^{* *}$ \\ *Department of Nursing, College of Medicine and Allied Sciences, King Abdulaziz \\ University, Jeddah, Saudi Arabia, ${ }^{* *}$ South Bank University, United Kingdom.
}

\begin{abstract}
The purpose of this study was to evaluate the effects of a 5-day (20 hour) maternal nutrition nursing continuing education (CE) programme on Diploma nurses' knowledge working in Primary Health Care Centres. Twenty nurses from Primary Health Care Centres (PHCC) completed a questionnaire designed for the purpose of this study before and after the participation in the CE Programme. Post-test scores were significantly higher than pre-test scores. One hundred percent of the nurses felt that their knowledge concerning maternal nutrition improved to a better level as compared to pre-programme knowledge. About $85 \%$ still had average confidence to teach.
\end{abstract}

Keywords: Nursing continuing education, Evaluation, Maternal nutrition.

\section{Introduction}

Although pregnancy is a normal physiological process, it is associated with certain risks to the life and health of both mother and baby. These risks could be prevented through appropriate antenatal care. Maternal nutrition is an important influence affecting the course and outcome of pregnancy ${ }^{[1]}$. Studies reported have shown the influence of nutritional intake on the outcome of pregnancies and the health of the moth$\mathrm{er}^{[1,2]}$. It is well documented that an adequate diet before and during pregnancy have a significant effect on the nutritional status of both the mother and the foetal outcome. During pregnancy the women's body needs an extra store of nutrients for the foetus' growth and development and to build up the women's own body reserves. A good diet

Correpondence \& reprint requests: Dr. Shadia A. H. Yousuf, P. O. Box 80215, Jeddah 21589, Saudi Arabia. Accepted for Publication: 20 July 1999. Received: 24 January 1999. 
that provides adequate amounts of calories and essential nutrients is necessary for the support of the maternal body tissues and for the growth and development of the foetus. Pregnant women need extra protein, calories, calcium, iron, iodine, folate, and vitamin $\mathrm{C}^{[2]}$. Malnutrition or obesity during pregnancy are conditions that may induce risks such as intrauterine growth retardation, toxaemia, anemia, low birth weight babies, and premature babies $^{[1,3,4,5,6]}$.

Numerous appropriate actions may avoid an unnecessary bad outcome of pregnancy and improve maternal nutrition. These include providing birth spacing, education, and giving nutritional education to women. In order to ensure that pregnant women are consuming an adequate intake of food, the health professionals need to have an important role in educating women about intake, and providing adequate care. Since nurses are one of the major health professional groups working in PHCC who have more opportunity in meeting the women, they have the responsibility to teach and guide pregnant women in matters concerning pregnancy during the routine antenatal care. The World Health Organization (WHO) recommends nurses and midwives to become enablers and facilitators in order to provide appropriate information and guidance to educate the communities to help themselves within their social and cultural limitations ${ }^{[7]}$. A new role of nursing has been proposed in nursing practices and advocated by WHO to cope with the new trend of nursing care in health services. In antenatal clinics, the nurses need to know the changes that take place in the women's body during pregnancy and the need of nutrition during pregnancy to provide sound nutritional advice. Knowledgeable nurses could help to spot the complications early and to give the women appropriate advice. The health educational role is one of the nurses' roles $^{[7]}$. The $\mathrm{Di}^{-}$ rector of PHCC in Saudi Arabia stated that their nurses have such a role ${ }^{[8]}$.

Women in Saudi Arabia tend to experience more pregnancies ${ }^{[9]}$ and anaemia is a common problem in pregnancy ${ }^{[9,10]}$. Therefore, the nurses in antenatal care need to be evaluated and prepared for their role in PHCC. After assessing the knowledge level of diploma nurses who are working in PHCC through personal communication with the Director of nursing and the supervisors, it was found that the majority of the nurses have a low level of general knowledge about maternal nutrition. Knowledge is the base to influence the attitude and behaviour of the nurses and subsequently might influence the care given by the nurses. In order to have a result-oriented programme, an evaluation is an essential step. The process of evaluation is complex. Although the goals of most types of educational endeavours in nursing are the same, the desired changes in the learner's behaviour, aiming to improve their practice, may therefore provide higher quality care. The evaluation process is recognised as an essential component of the educational process. Gosnell ${ }^{[11]}$ identified four types of CE evaluation strategies: (1) perceptual-option evaluation; (2) behavioural performance evaluation; (3) measurable learning evaluation; and (4) outcome-results evaluation. He stated that type 1 and 3 have showed positive effects of CE programmes on participants' opinions and on their cognitive learning. The types 2 and 4 evaluate the effects of the CE programme on nurses' behaviour and practice. Since nursing is a practice discipline, it is important to 
evaluate the effect of CE programmes on actual nursing performance. This study will use a measurable learning evaluation where the knowledge part is assessed only.

The purpose of the study was to evaluate the effects of a short-term CE programme on nursing knowledge of maternal nutrition. The following objects were aimed to:

1) collect demographic data regarding nurses working in PHCC in the antenatal clinic.

2) assess factors that influence nurses' knowledge.

3) identify nurses' source of knowledge.

4) compare pre- and post-programme data regarding the nutritional knowledge of the nurses.

\section{Materials and Methods}

Design and sample: The CE programme consisted of 20 hours of classes offered to 20 nurses in 5 days. They were recruited via the Director of PHCC in Jeddah, Saudi Arabia. The nature of the programme had been explained to all the nurses on the first day of the programme to obtain their consent. The nurses also were informed that they would be contacted for a follow-up test. The nurses were ensured that the result of the pre-test knowledge scores would be kept confidential.

Initial needs assessment had shown that PHC nurses had little information regarding maternal nutrition. A schedule was developed with relevant contents of material after consulting experts in the fields of nursing, obstetric, and the in-service department of PHCC. Table 1 shows the list of units covered during the programme. Lecture discussion methods were utilized to allow the nurses' participation to share their feelings, thoughts, and experience related to each topic. At the end of each session, a formative assessment was used to evaluate their progress. All the nurses were asked to complete a pre-test on their knowledge about maternal nutrition before the programme. A posttest was completed immediately after the programme and a second follow-up test was conducted after 6 months of the programme. The 6-month point was selected arbitrarily. Six months after the programme was offered, individual participants were contacted by telephone, and asked to continue in the study and they were informed that they would be contacted by the investigator to fill another set of questionnaires. The questionnaires were sent to each participant for completion. The investigator has not measured outcomes of the programme on maternal and child services as a cause-effective relationship.

Instrument: The nutritional knowledge questionnaire was developed after reviewing related literature by the investigator. The questionnaire included two main sections. The first section included personal background of the nurses in the form of open-ended questions (Table 1). 
TABLE 1. Content outline for CE classes.

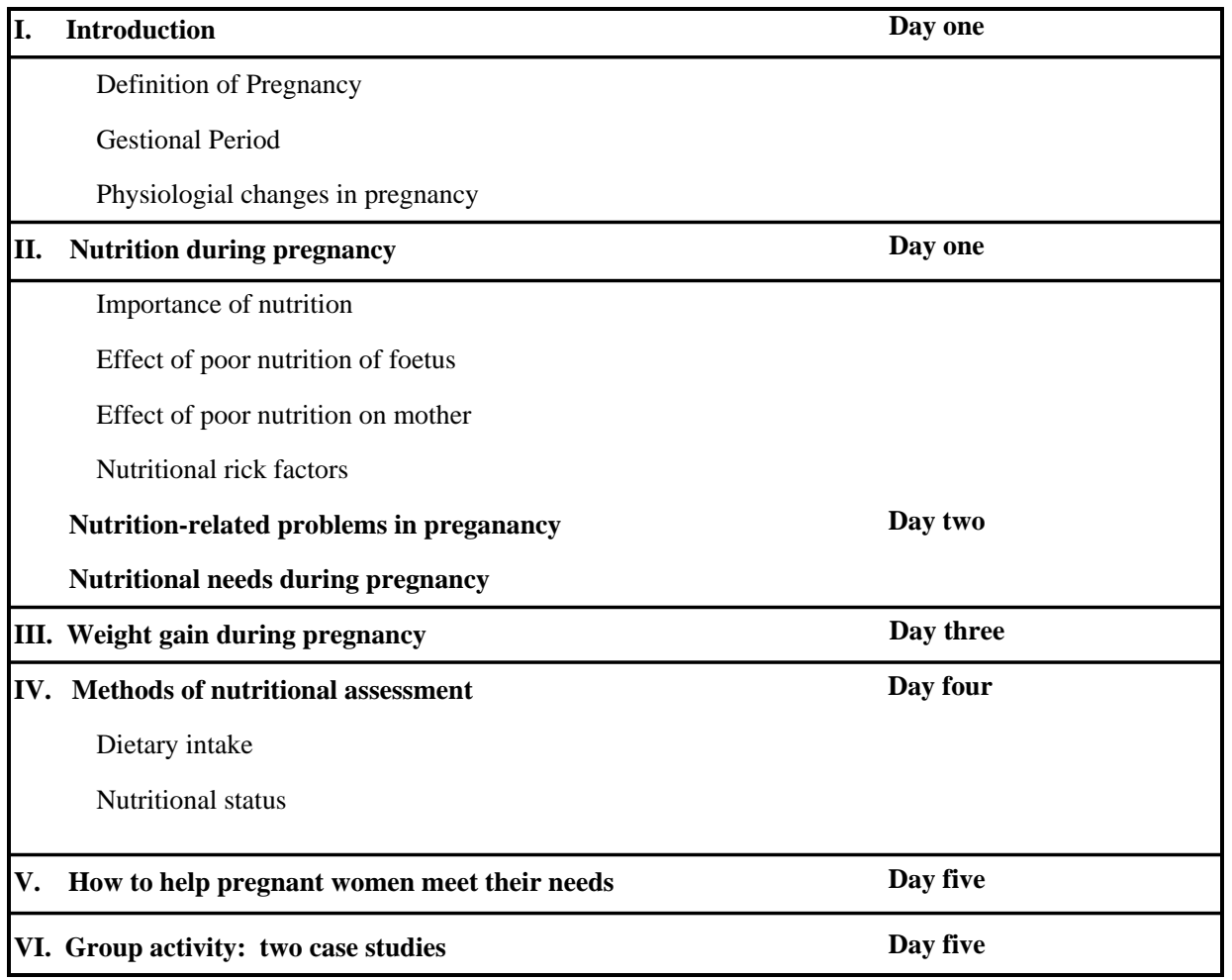

The second section included 37 items on nutritional knowledge. Each item is provided with possible responses of "yes", "no", and "I don't know". Answers are scored with 2,1 , and 0 respectively.

Reliability of of the instrument was tested using test-retest scores on a group of 10 diploma nurses selected randomly and the correlation was 0.85 found on randomly selected items. Validity of the instrument was assessed by a group of experts in the field of nursing, obstetric, and primary health care physicians.

Limitation: The sample was small which cannot be generalized to all the nurses in Saudi Arabia and there was no control group to be compared with.

\section{Results}

The number of years that the nurses had been practising ranged from 2 to 25 years with a mean duration of 8.3 years $(\mathrm{SD}=6.01)$. The mean age of the nurses is 29.8 years with a standard deviation (SD) of 4.697. The mean knowledge scores obtained by the nurses before the programme was 51 with SD of 5.61. The highest mean scores is 74 (Table 2). 
TABLE 2. Mean and standard deviation of nurses' years of experience, age, and knowledge scores.

\begin{tabular}{|c|c|c|}
\hline Items & Mean \& Standard Deviation & Age Range \\
\hline Years of experience & $8.30(6.01)$ & $2-25$ \\
\hline Age & $29.80(4.697)$ & $20-39$ \\
\hline Knowledge scores & $51.00(5.61)$ & $40-60$ \\
\hline
\end{tabular}

There was no significant correlation between the number of years they had been practicing and their nutritional knowledge scores as indicated by their total scores on each group of questions. The result showed a significant relationship between the nurses' age and the scores obtained from the questions related to toxaemia (Table 3).

The majority of nurses $(95 \%)$ had more than $50 \%$ correct knowledge on milk intake. Nearly $65 \%$ of the nurses had less than a $50 \%$ score on vitamin C. The majority of the nurses $(95 \%)$ scored more that $50 \%$ of the total score in questions related to iron intake. In relation to protein and amino acid questions, the majority of the nurses $(80 \%)$ obtained knowledge scores of less than $50 \%$ of the total scores. The majority of the nurses in the study $(65 \%)$ had low knowledge scores related to toxaemia (Table 4).

The majority of the nurses had poor knowledge on protein, vitamin $\mathrm{A}$, vitamin $\mathrm{C}$ (Table 5). Eighty percent and $95 \%$ of the nurses did not know that meat is a source of essential amino acids and vitamin A respectively. About 95\% did not know that essential amino acid cannot be synthesized in the body and $75 \%$ did not know that an excess of vitamin A intake during early pregnancy may cause congenital abnormalities in the foetus. Ninety-five percent of the nurses knew that milk and milk products are rich in calcium but $75 \%$ were not aware of the recommended amount of calcium required for pregnant women and $70 \%$ did not know calcium is needed at the last trimester. Most knew that fibre intake is encouraged during pregnancy and that vegetables are an important source of fibre.

In relation to iron intake and anaemia during pregnancy, half of the nurses knew that iron tablets should be prescribed after the first trimester and $80 \%$ knew that pregnant women need more iron than non-pregnant women. But the majority $(75 \%)$ did not know that low iron during pregnancy may lead to foetal anaemia. Only $30 \%$ were not aware that green vegetables contain large amounts of iron (Table 6). Although all the nurses scored $50 \%$ and more in the total scores of questions related to weight gain, the majority $(85 \%)$ did not know that low maternal weight gain may be associated with premature babies. Fifty-five percent did not know that sudden weight gain may indicate toxaemia in pregnancy and $65 \%$ did know that low protein intake may lead to toxaemia (Table 7).

In comparing the nutritional knowledge scores of the nurses before and after the course, it was found that there was a significant improvement in their knowledge. The $\mathrm{t}$-test for the sample was performed to determine if nurses attained knowledge gained from the course in the form of pre-test and post-test assessment(Table 8). The difference in the knowledge scores of the nurses in the post-test and six month follow-up was also monitored. The p-values were more than 0.01 in most of the questions. It showed that the nurses' knowledge scores did not change significantly from the initial post-test. 
TABLE 3. Correlation of nurses' nutritional knowledge scores and their age and years of experience.

\begin{tabular}{|c|c|c|c|c|c|c|c|c|c|}
\hline \multicolumn{10}{|c|}{ Nutritional Knowledge } \\
\hline Correlates & $\mathrm{T} 1$ & $\mathrm{~T} 2$ & $\mathrm{~T} 3$ & $\mathrm{~T} 4$ & $\mathrm{~T} 5$ & $\mathrm{~T} 6$ & $\mathrm{~T} 7$ & $\mathrm{~T} 8$ & $\mathrm{~T} 9$ \\
\hline Age & 0.35 & 0.56 & 0.44 & 0.66 & 0.53 & 0.35 & 1.00 & $0.022 *$ & 1.00 \\
\hline Years of Experience & 0.85 & 0.49 & 0.51 & 0.68 & 0.25 & 0.15 & 1.00 & 0.25 & 1.00 \\
\hline
\end{tabular}

*Significance at 0.05 alpha

$\mathrm{T} 1=$ Total score of questions related to milk

$\mathrm{T} 2=$ Total score of questions related to vitamin D

$\mathrm{T} 3=$ Total score of questions related to protein

$\mathrm{T} 4=$ Total score of questions related to vitamin A

$\mathrm{T} 5=$ Total score of questions related to vitamin $\mathrm{C}$

T6 $=$ Total score of questions related to iron

$\mathrm{T} 7=$ Total score of questions related to effect of maternal diet

$\mathrm{T} 8=$ Total score of questions related to toxaemia

$\mathrm{T} 9=$ Total score of questions related to maternal weight gain

TABLE 4. Frequency distribution of nurses for each group of questions $(\mathrm{N}=20)$.

\begin{tabular}{|l|c|c|c|c|}
\hline \multicolumn{1}{|c|}{ Group of questions } & Scores $<50$ & Percentage $(\%)$ & Scores $>50$ & Percentage (\%) \\
\hline T1 (Milk) & 1 & 5 & 19 & 95 \\
\hline T2 (Vitamin D) & 4 & 20 & 16 & 80 \\
\hline T3 (Protein) & 16 & 80 & 4 & 20 \\
\hline T4 (Vitamin A) & 14 & 70 & 6 & 30 \\
\hline T5 (Vitamin C) & 13 & 65 & 7 & 35 \\
\hline T6 (Iron) & 1 & 5 & 19 & 95 \\
\hline T7 (Effects of maternal diet) & 0 & 0 & 20 & 100 \\
\hline T8 (Toxaemia) & 13 & 65 & 7 & 35 \\
\hline T9 (Maternal weight gain) & 0 & 0 & 20 & 100 \\
\hline
\end{tabular}

The nurses' evaluation on the effect of the programme on their knowledge before and after, and the influence on their confidence to teach pregnant women after the programme found that $5 \%$ of the nurses believed that they had poor maternal nutritional knowledge before the programme. The majority believed they had between average and good knowledge before the programme, $55 \%$ and $40 \%$ respectively. After the programme, they said that their knowledge had improved to good and excellent, $60 \%$ and $40 \%$ respectively. Regarding their confidence to teach pregnant women, $15 \%$ said they were average, $45 \%$ said good and $40 \%$ felt very confident to be able to teach women 
TABLE 5. Nurses' responses to nutritional knowledge in relation to protein, vitamin A \& $\mathrm{C}$ and milk intake $(\mathrm{N}=20)$.

\begin{tabular}{|l|c|c|c|}
\hline \multicolumn{1}{|c|}{ Items } & Correct & Incorrect & Do not know \\
\hline Meat as source of essential amino acid & $4(20 \%)$ & $5(25 \%)$ & $11(55 \%)$ \\
\hline Essential amino acid synthesis & $1(5 \%)$ & $11(55 \%)$ & $8(40 \%)$ \\
\hline Protein intake during pregnancy & $10(50 \%)$ & $2(10 \%)$ & $8(40 \%)$ \\
\hline Protein is used as a source of energy & $7(35 \%)$ & $7(35 \%)$ & $6(30 \%)$ \\
\hline Meat as vitamin A source & $1(5 \%)$ & $13(65 \%)$ & $6(30 \%)$ \\
\hline Vitamin A storage & $8(40 \%)$ & $5(25 \%)$ & $7(35 \%)$ \\
\hline Effect of excess vitamin A intake & $5(25 \%)$ & $10(50 \%)$ & $5(25 \%)$ \\
\hline Vitamin C storage & $9(45 \%)$ & $6(30 \%)$ & $5(25 \%)$ \\
\hline Vitamin C intake & $5(25 \%)$ & $5(25 \%)$ & $10(50 \%)$ \\
\hline Milk intake & $5(25 \%)$ & $15(75 \%)$ & 0 \\
\hline Foetus needs calcium at last trimester & $6(30 \%)$ & $13(65 \%)$ & $1(5 \%)$ \\
\hline
\end{tabular}

TABLE 6. Nurses' responses to nutritional knowledge in relation to iron $(\mathrm{N}=20)$.

\begin{tabular}{|l|c|c|c|}
\hline \multicolumn{1}{|c|}{ Items } & Correct & Incorrect & Do not know \\
\hline Iron tablet intake & $10(50 \%)$ & $10(50 \%)$ & 0 \\
\hline Need extra iron during pregnancy & $16(80 \%)$ & $4(20 \%)$ & 0 \\
\hline Anaemia & $17(85 \%)$ & $3(15 \%)$ & 0 \\
\hline Low maternal iron intake \& foetal anaemia & $5(25 \%)$ & $14(70 \%)$ & $1(5 \%)$ \\
\hline Green vegetables are rich in iron & $14(70 \%)$ & $4(20 \%)$ & $2(10 \%)$ \\
\hline
\end{tabular}

(Table 9). These results were similar when tested during the follow-up evaluation. Two nurses declined to participate in the follow-up post-test because they were on maternity leave. Of the remaining 18 nurses who could be reached, all but 3 immediately stated the ways they had used this programme. Of the 3 who did not use the programme, the first had moved to immunization, the second to dressing room, and the third did not comment.

Table 10 showed the nurses' sources of nutritional knowledge. The majority of the nurses claimed to obtain their nutritional knowledge from their basic training $(80 \%)$ with the second most common source being the mass media and professional colleagues $(65 \%)$. Only a few mentioned that experience and in-service training were their source of knowledge, 10 and 15\%, respectively. 
TABLE 7. Nurses' responses to nutritional knowledge in relation to weight gain during pregnancy ( $N=20)$.

\begin{tabular}{|l|c|c|c|}
\hline \multicolumn{1}{|c|}{ Items } & Correct & Incorrect & Do not know \\
\hline Ideal weight gain & $9(45 \%)$ & $10(50 \%)$ & $1(5 \%)$ \\
\hline Weight gain in first trimester & $14(70 \%)$ & $5(25 \%)$ & $1(5 \%)$ \\
\hline Equal weight gain among women & $16(80 \%)$ & $4(20 \%)$ & $0(0 \%)$ \\
\hline Maternal weight gain due to foetal weight & $10(50 \%)$ & $6(30 \%)$ & $4(20 \%)$ \\
\hline Low maternal weight gain and premature babies & $3(15 \%)$ & $15(75 \%)$ & $2(10 \%)$ \\
\hline Sudden weight gain and toxaemia & $9(45 \%)$ & $8(40 \%)$ & $3(15 \%)$ \\
\hline Protein intake and toxaemia & $7(35 \%)$ & $5(25 \%)$ & $8(40 \%)$ \\
\hline
\end{tabular}

TABLE 8. The mean, SD and t-test values for the knowledge change of nurses before and after the course.

\begin{tabular}{|l|cc|cc|c|}
\hline \multicolumn{1}{|c|}{ Items } & \multicolumn{2}{|c|}{ Pre-test (N=20) } & \multicolumn{2}{c|}{ Post-test (N=20) } & p \\
& Mean & SD & Mean & SD & \\
\hline Grand Total & 50.95 & 5.615 & 67.90 & 3.597 & 0.000 \\
T1 (Milk) & 4.45 & 0.686 & 5.90 & 0.308 & 0.000 \\
T2 (Vitamin D) & 3.05 & 0.686 & 3.35 & 0.745 & 0.163 \\
T3 (Protein) & 3.45 & 1.504 & 7.15 & 0.745 & 0.000 \\
T4 (Vitamin A) & 2.8 & 1.673 & 5.2 & 0.894 & 0.000 \\
T5 (Vitamin C) & 1.95 & 1.356 & 3.5 & 0.761 & 0.000 \\
T6 (Iron) & 7.95 & 1.191 & 9.5 & 0.889 & 0.000 \\
T7 (Effect of maternal diet) & 8.4 & 0.94 & 9.5 & 0.688 & 0.000 \\
T8 (Toxaemia) & 2.25 & 1.07 & 3.8 & 0.41 & 0.000 \\
T9 (Maternal weight gain) & 8.95 & 1.317 & 10.9 & 0.788 & 0.000 \\
\hline
\end{tabular}

*2 Tailed probability 
TABLE 9. Distribution of nurses' response according to their perception on the effect of the programme on their knowledge and confidence to teach.

\begin{tabular}{|c|c|c|c|c|c|c|}
\hline \multirow{2}{*}{ Categories } & \multicolumn{3}{|c|}{ Knowledge } & \multicolumn{2}{c|}{ Confidence to Teach } \\
\cline { 2 - 7 } & Pre & $\%$ & Post & $\%$ & Post & $\%$ \\
\hline Poor & 1 & 5 & 0 & 0 & 0 & 0 \\
\hline Average & 11 & 55 & 0 & 0 & 3 & 15 \\
\hline Good & 8 & 40 & 12 & 60 & 9 & 45 \\
\hline Excellent & 0 & 0 & 8 & 40 & 8 & 40 \\
\hline
\end{tabular}

TABLE 10. Nurses' sources of nutritional knowledge.

\begin{tabular}{|l|c|}
\hline \multicolumn{1}{|c|}{ Sources } & Percentage (\%) \\
\hline Basic Training & 80 \\
\hline Mass Media & 65 \\
\hline Professional Collegues & 65 \\
\hline In-Service Training & 15 \\
\hline Experience & 10 \\
\hline
\end{tabular}

*Total percentage is $>100$ because of multiple responses from each nurse.

\section{Discussion}

The study showed the deficient nutritional knowledge among the diploma nurses working in the two centres. This suggests that they need motivation to review their basic nutritional knowledge frequently in order to give appropriate nutritional advice for pregnant women. The study also showed that a well-designed programme based on the needs of the nurses could improve their knowledge and confidence in providing care. The differences between the pre- and post-test scores on the nurses'nutritional knowledge were statistically significant, the mean post-scores on the nurses' nutritional knowledge were higher than the pre-test scores. This difference suggests that the programme was effective in enhancing the nurses' knowledge about maternal nutrition, although it was a short course. The difference between scores on the pre-test and posttest was significant at 0.005 level indicating that the instruction programme at the cognitive level was effective in communicating concepts of nutrition related to pregnancy.

The nurses claimed that their nutritional knowledge was influenced by basic training and professional colleagues. This implies that these important individuals could provide valuable sources for nutritional teaching for the nurses and that the basic nursing course in nutritional requirements should be scrutinized. The curriculum of diploma nurses may not give nursing students enough of a period for practice and consequently 
causing less elaboration on maternal nutrition. This could be explained that the school expects the student would learn more about maternal nutrition when they work with pregnant women, but the study showed that the years of experience of the nurses did not influence their knowledge. The statistics showed no significant influences of age and years of experience on the nurses' knowledge.

Milk is an important source of calcium. This helped the nurses to instruct women to drink a lot of milk. The nurses needed to be informed more about protein through inservice training because their knowledge scores were poor in questions related to protein and amino acids. Protein is essential for the demand of maternal and foetal tissues formation and development ${ }^{[1,2]}$. Carbohydrates should be utilized during pregnancy as a source of energy instead of protein ${ }^{[2]}$. Some Saudi pregnant women avoid meat intake during pregnancy ${ }^{[12]}$, especially during the first four months because of nausea. The nurses need to have adequate knowledge on protein in order to help the women through proper counselling and advice.

Studies suggested that pregnant women should be cautious against excessive vitamin A intake. This may result in birth defect in early pregnancy ${ }^{[13,14]}$. Liver in general contains a high content of vitamin $\mathrm{A}^{[14]}$, especially lamb liver ${ }^{[15]}$. It is observed that Saudi women especially love to eat lamb's liver. Therefore, nurses in antenatal clinics need to be cautious to advise anaemic women to eat liver by specifying the amount that should be consumed per week. It is prudent for the nurses to encourage pregnant women to consume more green leafy vegetables in place of liver for iron.

The nurses' knowledge on iron appeared to be learned from their experiences in the clinics. It was casually observed during the collection of data that the nurses were more concerned about anaemia in women than other issues. When the nurses noticed low hemoglobin levels in the results of blood tests, they immediately instruct the women to eat foods rich in iron, but without any further dietary assessment. The anaemia is a common health problem among Saudi women especially during pregnancy ${ }^{[9.10]}$. In Saudi Arabia, an iron supplement and folic acid are routinely prescribed as a prophylactic for all pregnant women from the beginning of the $4^{\text {th }}$ month of gestation until postpartum $^{[16]}$. Iron supplements could reduce the complications that may happen due to anaemia, i.e., complications of postpartum haemorrhage, the incidence of premature deliveries, neonatal anaemia, and spontaneous miscarriages ${ }^{[1-6,17]}$.

Toxaemia in pregnancy endangers the woman and the foetus. It is one of the causes of maternal death in many developing and developed countries ${ }^{[18,19,20]}$. This deficit in toxaemia-related knowledge among nurses may be explained due to the lack of exposure to actual cases of toxeamia. Usually toxaemia in pregnancy is considered to be high risk and such women are referred to and seen by an obstetrician ${ }^{[21]}$. The nurses need to detect the early signs of toxaemia among the women during routine check-ups before they reach to the late stage. The early signs of toxemia are sudden weight gain, with oedema and albumin in the urine ${ }^{[22]}$. Pregnant women need to be informed about signs of toxaemia as this might help them to detect its early signs at home in order to seek medical attention. Unfortunately, the nurses in the study had poor knowledge in relation to toxaemia which needs to be rectified by the nursing in-service department.

The results demonstrated that the basic training of the diploma nurses is important. The subject of nutrition is taught independently in the first year in the nurses' pro- 
gramme. There is very little in the curriculum about nutrition during pregnancy. Maternal nutrition is taught and is incorporated into "maternity nursing" subjects but not in depth, since the aim of this nursing programme was to produce general nursing knowledge. Therefore, for those graduates who want to work in antenatal clinics, some special training and courses on pregnancy, health education, and nutrition would be recommended. There are no dieticians or health educators available in the primary health centres $^{[8]}$. The nurses have the major responsibility of teaching the PHCC clients according to their needs to provide necessary information ${ }^{[7]}$. The in-service training that is taken by the nurses needs to be further assessed and evaluated. Some factors that may prevent nurses to apply what they have learned could be due to the following: 1) the working environment because the number of women attending the clinic is large in some centres leading to limited time spent on evaluating the nutritional intake of each woman, and 2) the frequent transfer of nurses from one section to another leaving no time for them to apply what they had learned. With appropriate adjustment and sequential $\mathrm{CE}$, the nurses may become competent to provide suitable nutritional advice.

In conclusion, the programme resulted in positive changes in diploma nurses' knowledge in relation to maternal nutrition which developed their confidence. The results of this study suggest that the CE programme described enhances nurses' knowledge towards maternal nutrition.

The nurses' reports suggested a need to repeat this type of CE for the nurses to refresh their memories. There is a need to identify a way to enable more nurses of PHCC and those who work in the antenatal clinics in hospitals to attend such CE programmes. Nurses should be lifelong learners and have the opportunities for CE to maintain their quality in practice to put up with the changing demands of the health care environment. The basic training of the nurses is important which requires analysis and modifications applied accordingly. The findings suggest the requirement for other studies to follow the event of CE programmes and the following questions need to be asked:

1) What is the relationship between nurses' knowledge and their nursing care with pregnant women?

2) What are the effects of maternal nutritional programmes on the practice of nursing?

3) What additional methods could enhance nurses' learning and knowledge retention?

\section{Acknowledgment}

The author would like to acknowledge the nurses who participated in the programme and the assistance provided by the Director of PHCC and the Head of the In-Service Department who facilitated the author with use of their facilities in order to conduct this programme.

\section{References}

[1] Worthington-Roberts B, Williams SR. Nutrition in pregnancy and lactation. $5^{\text {th }}$ edn., St. Louis: Times, Mirror/Mosby 1993.

[2] Davis J, Sherer K. Applied nutrition and diet therapy for nurses. $2^{\text {nd }}$ edn., Philadelphia: W.B. Saunders 1994.

[3] Winick, M. Maternal nutrition and fetal growth. $P$ N 1986; 28: 30-31,34.

[4] Norton R. Maternal nutrition during pregnancy affects growth, development, and health. S $C N N$ 1994; 11: 10-14.

[5] Giotta MP. Nutrition during pregnancy: Reducing obstetric risk. J Perinat Neonat Nur 1993; 6: 1-12.

[6] Werbach MR. Nutritional influences on illness: toxaemia of pregnancy. Int J AC Med 1993; 5: 19.

[7] World Health Organization. Nursing Practice. Technical Report Series 860. Geneva: WHO 1996. 
[8] Al Mazrou Y, Al Shehri S, Rao M. Principle and practice of primary health care. Riyadh: M O H 1990.

[9] Khoja SM, Sadia H, Salem SI, Nasrat HA. Iron status in pregnant Saudi Arabian women in the Jeddah area. Saudi Med J 1994; 15: 43-47.

[10] Al-Akija W. Anemia among the primigravida women in the Asir Region, Saudi Arabia: an epidemiological study. Saudi Med J1996; 17: 70-72.

[11] Gosnell DJ. A conceptual model. Evaluating continuing nursing education. J Cont Edu Nurs 1984; 15: 9-11.

[12] Al-Kanhal MA, Bani IA. Food habits during pregnancy among Saudi women. Int J Vitam Nutr Res 1995 ; 65: 206-210.

[13] Golding AMB. Vitamin A and D. Health and Hygiene 1992; 13: 1.

[14] Thompson J. Nutrition in pregnancy. Nurs Times 1993; 89: 38-40.

[15] Sanders TAB. Vitamin A and pregnancy. Lancet 1990; 336: 1375.

[16] Ministry of Health. Annual Health Report. Riyadh: MO H 1994.

[17] Nair L. Maternal nutrition: an essential element of primary health care. Nurs J India 1989; 80: 69-76.

[18] Al-Meshari A, Chattopadhyay AK, Younes B, Anokute C. Epidemiology of maternal mortality in Saudi Arabia. Ann Saudi Med 1995; 15: 317-322.

[19] Population Reports. Mother's live matter: maternal health in the community. Population Reports 1988; XVI; 2.

[20] Royston E, Armstrong S. Preventing maternal deaths. Geneva: W H O 1989.

[21] Al Mazrou Y. Dalil al ameelin fil al marakis alseheeyah. Manual of Health Personnel Working in Primary Health Care Centres. Riyadh: M O H 1991.

[22] May KA, Mahlmeister, LR. Comprehensive Maternity Nursing: Nursing Process and the Childbearing Family. $2^{\text {nd }}$ edn., Philadelphia: J. B. Lippincott 1990. 


\section{تقييم برنامج التعليم المستمر للممرضات}

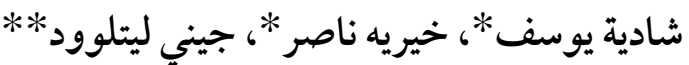

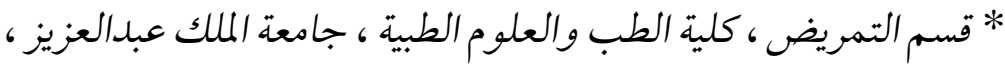

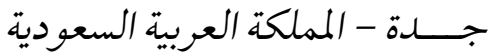

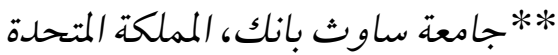

المستخلص. تهـدف هذه الدراسة بتقييم تأثير برنامج التعليم المستمر

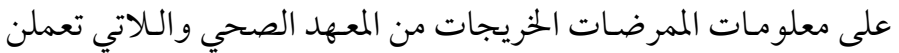

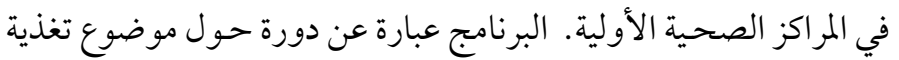

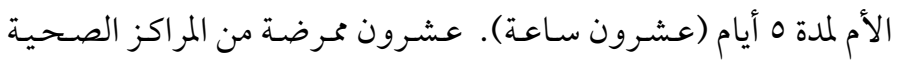

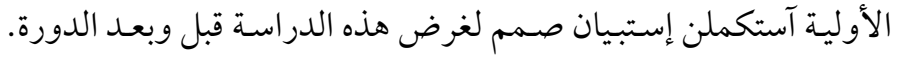

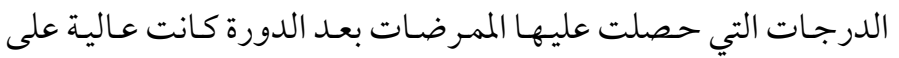

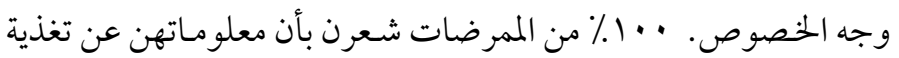

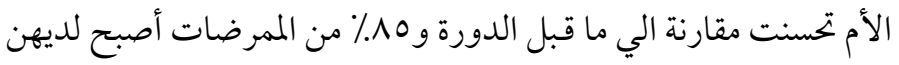

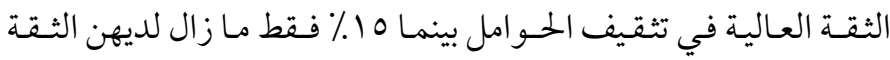
المتوسطة. 